\title{
The effect of time, shock stimulation, and stimulus uncertainty on the non-associative GSR'
} ROYER F. COOK, ${ }^{2}$ Kansas State Univer-
sity, Manhattan, Kans. 66502

Using an unpaired-stimuli procedure, 10 tones were presented to $\mathrm{Ss}$, interspersed with a mean of either 1 shock (range, 0-2) or 5 shocks (range, 4-6). Time between tones was either 100 or $200 \mathrm{sec}$. A fifth group also received a mean of 5 shocks between tones but the range was larger (from 2 to 8). The time interval variable showed no effect on the GSR. GSR to the tone was negatively related to the amount of shock, but also varied as a function of the amount of information in the stimulus sequence, as indicated both by a measure of informational uncertainty and by subjective predictive accuracy.

Recent GSR conditioning work has indicated the importance of understanding the nonassociative processes of the GSR, particularly as such processes may operate in the context of conditioning studies (Champion \& Jones, 1961; Prokasy \& Ebel, 1967; Stewart, Stern, Winokur, \& Fredman, 1969). However, only in the arousalattention literature (Berlyne, 1966; Lynn, 1966) has there been some identification of the stimulus conditions which specifically alter the nonassociative GSR.

Berlyne has investigated the stimulus characteristics which affect the orienting response (OR) specifically, and has culled them into three classes: psychophysical, ecological, and collative (Berlyne, 1966). Although researchers are careful to control the differential effects of psychophysical or ecological properties, the informative, collative properties have begun only recently to receive attention (Rescorla, 1967).

A study by Zimny, Stern, \& Fjeld (1966) and work from our laboratory (Cook, 1966) suggested that the amount of time between stimuli (ITI) and the number of noxious stimuli may affect the level of the nonassociative GSR. ${ }^{3}$ The research of Berlyne further indicates that stimulus uncertainty may be the common dimension underlying these variables. It was felt that the level of GSR would be positively related to the length of ITI and the number of shock presentations. At a more general level, it was expected that the level of GSR would vary as a function of the informational characteristics of the stimulus distribution.

\section{SUBJECTS}

Thirty-nine male and 31 female students in an introductory course at Kansas State
University served as Ss. Each received credit toward his grade.

\section{PROCEDURE}

Subjects were presented with a series of unpaired tones and shocks. The $2000-\mathrm{Hz}$ tones were delivered through a speaker located approximately $3 \mathrm{ft}$ behind and $2 \mathrm{ft}$ above $S$ at an intensity of $75 \mathrm{~dB}$ (re .0002 dynes $/ \mathrm{cm}^{2}$ ) for a duration of 500 msec. Constant white noise (off during tone presentation) was generated at a level of $60 \mathrm{~dB}$. The 60-cycle ac square-wave shock was delivered through a concentric disc electrode (Tursky \& Watson, 1965) on the left volar forearm with 500 -msec durations. Shock intensity was determined individually for each $S$ at a level judged by $S$ to be "irritating but not painful," and ranged from 2.2 to $4.3 \mathrm{~mA}$ over all Ss. Each $\mathrm{S}$ received 10 tones interspersed with shock. The ITI was controlled by means of Tektronix waveform generators.

In both Groups 1 and 2 the mean ITI was $100 \mathrm{sec}$ (range, 75-125 sec). In Group 1, S received an average of one shock (range, 0-2) between tones, while in Group 2, S received an average of five shocks (range, 4.6) between tones. In Groups 3 through 5 the mean ITI was $200 \mathrm{sec}$ (range, 175-225 sec). In Group 3, S received an average of one shock (range, $0-2$ ) between tones, while in Group $4 \mathrm{~S}$ received an average of five shocks (range, 4-6) between tones. Group 5 was similar to Group 4 except that the number of shocks presented between tones ranged from 2 to 8 .

Within the ITI the shocks were presented in a "restricted random" fashion: stimuli were never presented less than 15 sec apart in Groups 1 and 2, or less than $25 \mathrm{sec}$ apart in Groups 3, 4, and 5. With the exception of those ITIs in Groups 1 and 3 where one or zero shocks were presented in the ITI, stimulus intervals never exceeded $25 \mathrm{sec}$ in Groups 1 and 2 or $65 \mathrm{sec}$ in Groups 3,4, and 5. These limits permitted GSR recovery and prevented shock-tone associations by contiguity. Within these bounds, the temporal positions of the stimuli were allotted randomly.

\section{DEPENDENT MEASURES}

The GSR score used was the logarithm of micromhos conductance. Three different statistical measures were employed in the analysis of the data: magnitude (log micromhos conductance change occurring on a given trial); amplitude (total accumulated GSR over a block of 10 trials divided by the number of non-zero responses); and probability (number of non-zero responses divided by trial block length, or 10).

The GSR was recorded from the dermohmeter dial by $E$ after each tone presentation. A response was defined as any observable movement of the ohms indicator needle which was initiated approximately 1-2 sec after stimulus onset. Any responses initiated before or after this period were recorded as zero responses.

\section{RESULTS}

The GSR magnitude measures for Groups 14 are shown in Fig. 1. There appears to be an inverse relation between number of shock presentations and GSR level. There is also evidence of an interaction between trials and shock stimulation: Groups 2 and 4 (five shocks between tone stimulations) habituated more rapidly than Groups 1 and 3 (one shock between tone stimulations). There does not, however,

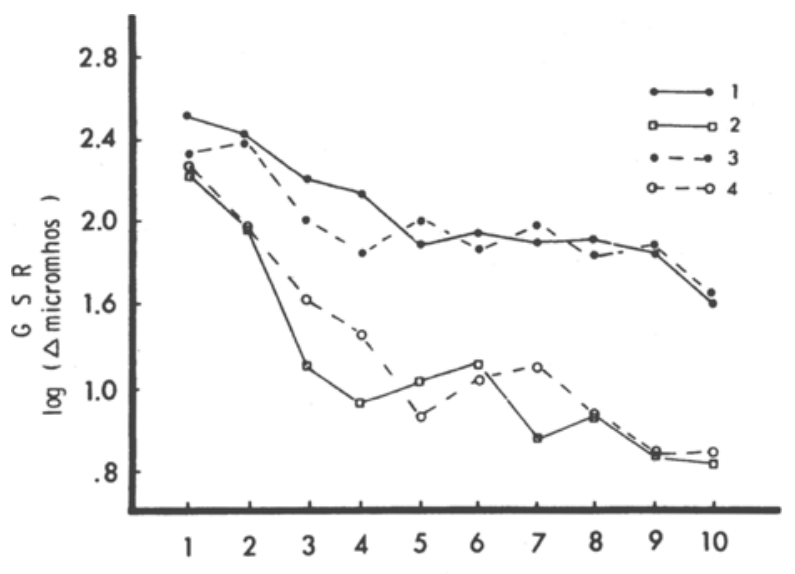

tone trials

Fig, 1. Mean magnitudes of primary groups. 


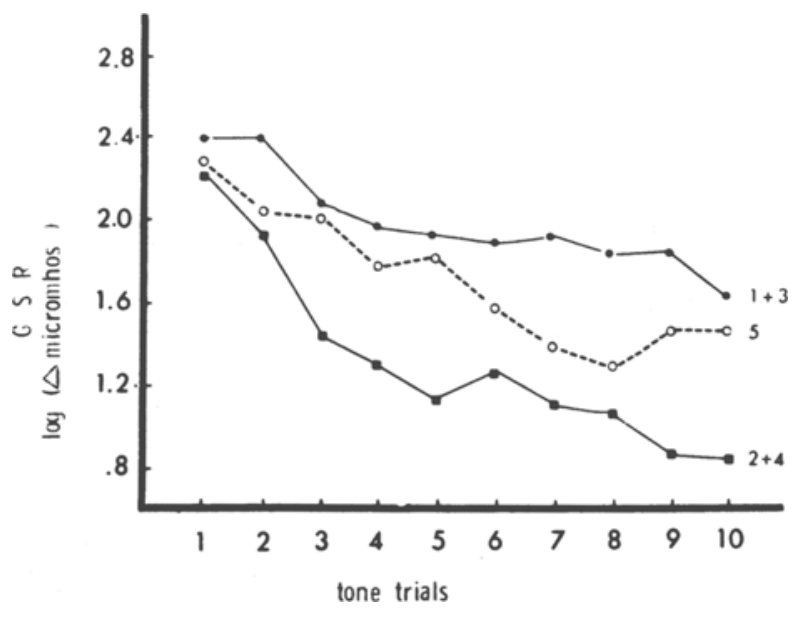

Fig. 2. Mean magnitudes of combined groups.

appear to be any effect of the time interval between the tone stimulations, for Groups 1 and 2 perform at approximately the same level as Groups 3 and 4 . The main effects of both the number of shocks $[F(1.56)=13.33]$ and trials $[F(9,504)=41.57]$ were significant as well as the Trials by Shock interaction $[F(9,504=4.16]$. The effect of ITI, on the other hand, was nonsignificant $[F(1,56)=.004]$.

A finer grain analy sis was provided by the measures of amplitude and probability. Because the amplitude measure does not include zero responses, a trial-by-trial analysis would have eliminated many Ss. Therefore, the trials variable was eliminated for both the amplitude and probability analyses. The effect of number of shocks on amplitude was significant $[F(1,56)=20.46]$, while its effect on response probability only approached significance $[F(1,56)=3.303]$. Neither the effect of time nor the Time by Shocks interaction were significant on the amplitude or probability measures.

Figure 2 combines Group 1 with 3 and Group 2 with 4 for the purpose of comparing these with Group 5 on the magnitude measure. The latter group performed at a level intermediate to the other two groups, despite the fact that Ss received an average of five shocks between tones just as in Groups 2 and 4. Analy ses of these data showed that Groups 1 and 3 were not significantly higher than Group 5 $[\mathrm{t}(38)=1.27]$, but that Group 5 was significantly higher than Groups 2 and 4 $[\mathrm{t}(38=2.05]$.

\section{DISCUSSION}

Most Ss became completely adapted to the shock before the session was over. The typical $S$ emitted a higher GSR to the tone than to shock. (Unfortunately there are no recorded quantitative data to verify this). The GSR to the tone was, then, nonassoci- ative; it was not the anticipation of shock, but the failure to anticipate the tone which effected the tonal response. In this connection, Prokasy \& Ebel (1967) have suggested that amplitude effects are indica tive of nonassociative variation in the GSR. That the present effects were most clearly manifested in the amplitude scores supports the contention that the processes influenced were largely nonassociative.

The increase in the number of shock stimulations appears to result in habitu ation. Ss who received only one shock stimulation (Groups 1 and 3) responded with greater amplitude to the tone than those who received five shocks. However, two occurrences preclude a simple explanation at the frequency/habituation level. First, the response decrement was effected through the presentation of a different stimulus (the shock, not the tone). It has been generally assumed that the interpolation of a different stimulus produces a dishabituation of the response (Sokolov, 1963: Thompson \& Spencer, 1966). Furthermore, if the process were a case of simple response habituation, Group 5 should have performed at the same level as Groups 2 and 4 . This was not the case, and the essential difference between Group 5 and Groups 2 and 4 was that in Group 5 the occurrence of the tone was more uncertain. Uncertainty Analysis

In Groups 2 and 4 most of the stimuli could be predicted by S. Certainly this was true of the first four shocks in a one-shock sequence. Consequently, one would suspect that with such opportunity for prediction. there would be fewer orienting responses in these groups than in the one-shock groups, where $S$ could not predict the stmuli $u$ ith certainty at any time. This uncertinity interpretation appears particularly plausible in light of the performance of Group 5. where predictability would seem to he at an intermediate level.
To support this contention, the stimulus sequences were analyzed to $y$ ield the average number of bits/stimulus (Garner, 1963). The Groups 1 and 3 sequences (highest GSR) delivered .53 bits/stimulus; the Group 5 sequences (intermediate GSR), .31 bits/stimulus; and the Groups 2 and 4 sequences (lowest GSR), .23 bits/stimulus. Therefore, on an objective informational basis, the level of GSR varies as a function of the average information delivered by the stimuli.

To support the "objective" data an estimate of the amount of subjective uncertainty contained in the sequences was obtained by asking another group of Ss to predict the stimulus sequences used in the present study.

Five Ss presented with the Group 2 sequences correctly predicted the tone a total of 34 times. In contrast, the $10 \mathrm{Ss}$ presented with the Groups 1 and 5 sequences correctly predicted the tone a total of 19 and 21 times, respectively. A Kruskal-Wallis test revealed both Group 5 and Group 1 to differ significantly from Group $2[\mathrm{U}(5,5)=3]$. These data parallel the analyses of the GSR scores and reflect the average amount of uncertainty contained in the sequences.

Sokolov's (1963) "neuronal model" theory of the OR maintains that as a stimulus is received, a cortical model is constructed which incorporates the essential parameters of the stimulus. If a second stimulus is presented which differs in some degree from the previous stimulus (actually the cortical model of that stimulus) an OR will occur. Although there is considerable support for Sokolov's theory (Berlyne, 1961; Berlyne, 1966; Sokolov, 1963), a more complex, dynamic OR process would seem to account for the dat a more plausibly. Unger (1964) has shown that if an individual becomes habituated to a sequence of numbers, an OR will occur upon presentation of a formerly habituated number now out of sequence. The system may work in the following manner: As $S$ receives a sequence of different stimuli (as in both Unger's work and the present research), he initially produces ORs to a stimulus until a cortical model for each stimulus is constructed or located. As S learns the sequence, he is serially linking each model; one might say that he is "at the right model at the right time." However, if a stimulus is now presented out of sequence (stimulus uncertainty), an OR will occur because the stimulus now does not match the current model

Thi, implies that OR tendencies will incressic as some function of the amount of uncertainty attached to the stimulus. Such an interpretation is consistent with the results of this experiment, i.e., the average 
amount of information (bits/stimulus) contained in a stimulus sequence accounts for a significant portion of the variance in GSR level.

The ineffectiveness of the ITI variable was unexpected and is probably attributable to the small range of values (100 sec vs $200 \mathrm{sec}$ ). More data are needed before any firm conclusions are drawn concerning this variable.

These data further serve to call into question the wisdom of research which disregards the pattern of the stimulus complex and chooses to deal only with simple contiguity relationships. This does not suggest that it is inappropriate to research the "associational moment," but that one can ignore neither the distribution in which that moment is embedded nor the cortical representation of the stimulus distribution which $\mathbf{S}$ develops.

\section{REFERENCES}

BERLYNE, D. E. Collative stimulus properties and the orientation reaction. International Congress of Psychology, 1966, 18, 84-102.

CHAMPION, R. A., \& JONES, J. E. Forward, backward, and pseudoconditioning of the GSR. Journal of Experimental Psychology, 1961,62. 58-61.

COOK, R. F. Pseudoconditioning of the GSR. Unpublished Masters thesis, Kansas State University, 1966.

GARNER, W. R. Uncertainty and structure as psychdogical concepts. New York: John Wiley, 1962.
PROKASY, W. F., \& EBEL, H. C. Three components of the elassically conditioned GSR in human subject. Joumal of Experimental Psychology, 1967, 73, 247-256.

RESCORLA, R. A. Pavlovian conditioning and its proper control procedures. Psychological Review, 1967, 74, 71-80.

SOKOLOV, E. N. Perception and the conditioned reflex. New York: Pergamon Press, 1963.

STEWART, M. A., STERN, J. A., WINOKUR, G. \& FREDMAN, S. An analysis of GSR conditioning. Psychological Review, 1961, 68, 60-67.

THOMPSON, R. F., \& SPENCER, W. A. Habituation: A model phenomenon for the study of neuronal substrates of behavior. Psy chological Review, 1966, 73, 16-43.

TURSKY, B., \& WATSON, P. D. Controlled physical and subjective intensities of electric shock. Psy chophysiology, 1964, 1, 151-162.

UNGER, S. M. Habituation of the vasoconstrictive orienting reaction, Journal of Experimental Psy chology, 1964, 67, 11-18.

ZIMNY, G. H., STERN, J. A., \& FJELD, S. P. Effects of CS and UCS relationships on electrodermal response and heart rate. Joumal of Experimental Psychology, 1966, 72, 177-181.

\section{NOTES}

1. This report is based on the author's doctoral dissertation (Cook, 1968) where additional information may be found. The research was performed while the author was a USPHS Predoctoral Fellow. The author would like to thank Merrill E. Noble for his assistance and guidance through all phases of the research.

2. Now at the American Institutes for Research, Washington office.

3. "Nonassociative" does not imply a complete lack of association between two types of stimuli but that the stimulus distributions are such that the one could not serve as a cue for the occurrence of the other. stimulus-seeking tendencies as measured by the Sensation-Seeking Scale (SSS) (Zuckerman et al, 1964) might also positively co-vary in their rate of adaptation to stimulation. According to Quay (1965), this may constitute one basis for differing needs for stimulational variety. If adaptation (satiation) were the process underlying both the VT effect and individual differences in stimulus-seeking, then the rate of perceived verbal transformations should be positively correlated with the SSS score. To test this prediction was the primary purpose of the present study. Furthermore, the experiment was so planned as to provide information regarding: (1) the feasibility of a group method of studying the VT effect, (2) the effect of disclosure-nondisclosure instructions upon the VT effect, and (3) the course of the phenomenon over time.

\section{METHOD}

The SSS was administered to all $\mathrm{Ss}$ in three classroom groups, and shortly thereafter they were exposed to a 4 -min tape recording of the word "distress" repeated every $1.15 \mathrm{sec}$. The tape was manufactured by playing a closed loop of tape with one repetition of the word and rerecording it upon a second tape recorder. This insured that the successive repetitions of the word were identical. The tape was played at the front of the classroom with sufficient sound intensity to be clearly audible in all parts of the room. The Ss were provided with an answer sheet ruled into four portions corresponding to the 4 successive minutes of the tape. The Ss were instructed to make a tally mark upon the sheet each time they heard a change on the tape, with each alternation between different forms counting as a change. At the end of each minute of stimulation, the Ss were instructed by the examiner to "switch to the next box." At the end of the 4-min tape they were asked to write down all the different forms they had heard, including nonsense forms.

The three groups of Ss tested had the following characteristics:

Group ND1 (nondisclosure): $\mathrm{N}=18$, mean age 37.5 , mean education $16+$ years. This consisted of graduate students in a learning course. The repetitive nature of the tape was not revealed.

Group ND2 (nondisclosure): $N=31$, mean age 22.55 , mean education $14+$ years. This consisted of undergraduate students in an educational psychology course. The nature of the tape was not disclosed to this group.

Group D (disclosure): $\mathrm{N}=36$, mean age 22.22 , mean education $14+$ years. This undergraduate educational psychology class was instructed regarding the repetitive nature of the tape but was told that people nevertheless tended to hear changes under these conditions.
When a single tape-recorded word is repeatedly presented to an $S$ at fairly high rates, he reports spontaneous changes in the which are markedly different from the actual recorded word (Warren \& Gregory,

Warren (1968) has recently reviewed the ating and some of the theor tion" (VT) phenomenon. One possible explanatory at tempt which he discusses may cube) as analogous phenomena. Accor , the VT effect may be considered reflect semantic satiation to a particula auditory stimulus, with resulting perceptual reorganization producing a new percept.

The present experiment was planned within the context of a satiation analysis. It was reasoned that people who varied in 